\title{
Condições higiênico-sanitárias e perfil da comunidade microbiana de utensílios e mesas higienizadas de um serviço de alimentação localizado no Rio de Janeiro
}

\section{Hygienic-sanitary conditions and microbial community profile of tables and tableware of a food service located in Rio de Janeiro}

Aline Gomes de Mello de Oliveira ${ }^{1 *}$ (1), Lauro Melo², Daniela Betzler Cardoso Gomes ${ }^{3}$, Raquel Silva Peixoto ${ }^{3}$, Deborah Catharine de Assis Leite ${ }^{3}$, Selma Gomes Ferreira Leite ${ }^{2}$ Luciléia Granhen Tavares Colares ${ }^{1}$, Marco Antônio Lemos Miguel ${ }^{3}$

\footnotetext{
${ }^{1}$ Universidade Federal do Rio de Janeiro (UFRJ), Instituto de Nutrição Josué de Castro, Rio de Janeiro/RJ - Brasil ${ }^{2}$ Universidade Federal do Rio de Janeiro (UFRJ), Escola de Química, Rio de Janeiro/RJ - Brasil

3Universidade Federal do Rio de Janeiro (UFRJ), Instituto de Microbiologia Paulo de Góes, Rio de Janeiro/RJ -

Brasil
}

*Corresponding Author: Aline Gomes de Mello de Oliveira, Universidade Federal do Rio de Janeiro (UFRJ), Centro de Ciências da Saúde, Instituto de Nutrição Josué de Castro, Av. Carlos Chagas Filho, 373, Bloco J, $2^{\circ}$ andar, Ilha do Fundão, CEP: 21941-902, Rio de Janeiro/RJ - Brasil, e-mail: alinemello@nutricao.ufrj.br

Cite as: Oliveira, A. G. M., Melo, L., Gomes, D. B. C., Peixoto, R. S., Leite, D. C. A., Leite, S. G. F., Colares, L. G. T., \& Miguel, M. A. L. (2019). Hygienic-sanitary conditions and microbial community profile of tables and tableware of a food service located in Rio de Janeiro. Brazilian Journal of Food Technology, 22, e2018097.

https://doi.org/10.1590/1981-6723.09718

\section{Resumo}

O objetivo deste estudo foi avaliar as condições higiênico-sanitárias e o perfil da comunidade microbiana dos utensílios e das mesas de um serviço de alimentação localizado no município do Rio de Janeiro. A caracterização do processo de higienização dos utensílios (pratos, bandejas e talheres) e das mesas foi realizada por observação sistemática. Verificou-se que os utensílios eram lavados em máquina de lavar e as mesas, manualmente. Após a higienização, os utensílios apresentavam umidade e resíduos de alimentos. Pelo método dependente de cultivo, foram analisadas 126 amostras higienizadas (utensílios: $n=90$ e mesas: $n=36$ ). Pesquisaram-se bactérias mesófilas, coliformes, Escherichia coli, Staphylococcus aureus e fungos. Das amostras analisadas, $100 \%$ dos utensílios e $80 \%$ das mesas apresentaram contagens microbianas superiores ao recomendado na literatura, estando em condições higiênico-sanitárias inadequadas. E. coli foi isolada nos utensílios e $S$. aureus, nas mesas. Pelos métodos independentes de cultivo (PCR-DGGE e sequenciamento da subunidade $16 \mathrm{~S}$ do $\mathrm{rRNA}$ ), foram analisadas 36 amostras (utensílios: $\mathrm{n}=27$ e mesas: $\mathrm{n}=9$ ). Klebsiella sp. e Acinetobacter sp. Foram detectadas em todas as amostras, Citrobacter sp. sobre as mesas e Aeromonas hydrophila, nos talheres. Houve falha no processo de higienização, que foi confirmada pelas análises realizadas, que evidenciaram a presença de microrganismos 
indicadores e patogênicos, que podem causar a perda da qualidade das refeições, assim como danos à saúde dos comensais. Desta forma, é necessário adequar o processo de higienização, a fim de minimizar o risco de contaminação e o surto de doenças transmitidas por alimentos (DTA).

Palavras-chave: Contaminação microbiana; Serviços de alimentação; Segurança dos alimentos; Superfícies.

\begin{abstract}
The objective of the study was to evaluate the hygienic-sanitary conditions and the microbial community profile of tables and tableware of a food service located in the city of Rio de Janeiro. The characterization of the sanitation process of the tableware (plates, trays and cutlery) and the tables was carried out by systematic observation. The tableware were washed in washing machine and the tables, cleaned by hand. After this process, the tableware presented moisture and food residues. For the culture-dependent method, 126 sanitized samples (tableware: $n=90$ and tables: $\mathrm{n}=36$ ) were analyzed. Mesophilic bacteria, coliforms, fungi, Escherichia coli and Staphylococcus aureus were investigated. $100 \%$ of the sampled tableware and $80 \%$ of the sampled tables presented microbial counts higher than recommended in literature. The surfaces were in inadequate hygienic-sanitary conditions. E. coli was isolated in the tableware and $S$. aureus in the tables. By independent culture methods (PCR-DGGE and 16S rRNA sequencing), 36 samples (tableware: $\mathrm{n}=27$ and tables: $\mathrm{n}=9$ ) were analyzed. Klebsiella sp. and Acinetobacter sp. were detected in all samples, Citrobacter sp. was found on the tables and Aeromonas hydrophila in the cutlery. Results showed that the analyzed surfaces had indicative and pathogenic microorganisms, which can cause loss of quality in meals, as well as damages to the consumers' health. Therefore, it is necessary to adapt the tableware and tables hygiene process in order to minimize the risk of contamination and food disease outbreaks.
\end{abstract}

Keywords: Microbial contamination; Food service; Food safety; Surfaces.

\title{
1 Introdução
}

As transformações ocorridas no cotidiano da população, como a ampliação da jornada de trabalho, a inserção da mulher no mercado de trabalho e a urbanização contribuíram para o desenvolvimento do setor de alimentação coletiva (Rodrigues \& Sabes, 2006; Leal, 2010).

O crescimento do setor pode ser observado pelo número de refeições realizadas fora do lar. No ano de 2017, foram fornecidas cerca de 16 milhões de refeições por dia, representando um aumento de $6 \%$ em relação ao ano de 2016. Além disso, foram oferecidos 180 mil empregos diretos e consumidos, aproximadamente, 12,4 mil toneladas de gêneros alimentícios (Associação Brasileira das Empresas de Refeições Coletivas, 2017).

$\mathrm{O}$ aumento do número de refeições realizadas fora do lar tem contribuído para a ocorrência dos surtos de doenças transmitidas por alimentos (DTA), que são um importante problema de Saúde Pública, tanto nos países desenvolvidos quanto naqueles em desenvolvimento (World Health Organization, 2018). Nos Estados Unidos da América, no ano de 2016, houve 24.029 casos de DTA, com 5.512 hospitalizações e 96 mortes (Centers for Disease Control and Prevention, 2016). No Brasil, foram reportados 5.252 casos de surtos DTA, entre os anos de 2010 e 2017 (Brasil, 2017). As DTA estão relacionadas com falhas que podem ocorrer durante o processo produtivo de refeições, incluindo a deficiente higienização dos alimentos e das superfícies (Brasil, 2010; Ebone et al., 2011; São José, 2012).

A importância do controle higiênico-sanitário dos equipamentos e utensílios dos serviços de alimentação pode ser evidenciada pelos estudos realizados por Coelho et al. (2010), que isolaram Bacillus cereus nas superfícies de bancadas, equipamentos e utensílios, e nas mãos de manipuladores de restaurantes comerciais do município de Viçosa, Minas Gerais. De forma semelhante, Cunningham et al. (2011) isolaram Escherichia coli das mesas de refeições e dos pratos, cortadores e placas de corte, em serviços de alimentação da 
Universidade de Minnesota - EUA. Salmonella Enteritidis também foi isolada em amostras de alimentos e nas superfícies de serviço de alimentação por Chatt et al. (2017).

Cabe ressaltar que os microrganismos deterioradores de alimentos e os patogênicos podem aderir às superfícies e permanecer viáveis, mesmo após o processo de higienização, acarretando a perda da qualidade das refeições produzidas, além de aumentar o risco da ocorrência de surtos de DTA (Rode et al., 2007; Kochanski et al., 2009; Kasnowski et al., 2010).

Dessa forma, é necessário que os gestores dos serviços de alimentação realizem o controle e a avaliação do processo de higienização - que envolve as etapas de limpeza e sanitização - das superfícies, para assegurar as condições higiênico-sanitárias das mesmas, de forma que não sejam fonte de contaminação no estabelecimento.

Diante do exposto, o presente estudo objetivou avaliar as condições higiênico-sanitárias e o perfil da comunidade microbiana dos utensílios e das mesas de um serviço de alimentação localizado no município do Rio de Janeiro, Brasil.

\section{Material e métodos}

O estudo foi realizado entre os anos de 2013 e 2014, em um serviço de alimentação (SA) localizado no município do Rio de Janeiro, Brasil. O SA servia aproximadamente 3.500 refeições no período do almoço e atendia à população em vulnerabilidade social, que incluía os moradores de rua e os trabalhadores informais de baixa renda. A pesquisa foi aprovada pelo comitê de ética e pesquisa da Universidade Federal do Rio de Janeiro (Protocolo n. ${ }^{\circ}$ 118/2010) e foi conduzida da seguinte forma:

\subsection{Caracterização do processo de higienização dos utensílios (pratos de cerâmica, bandejas de polipropileno e talheres de aço inoxidável) e mesas do salão de refeições}

Foi realizada por observação sistemática (Alvarez, 1991), para verificar a frequência e o método utilizado na higienização das superfícies dos utensílios e das mesas, assim como o emprego de produtos saneantes e se os mesmos eram regularizados pelo Ministério da Saúde, conforme prevê a Resolução - RDC n. ${ }^{\circ}$ 216/2004 da Agência Nacional de Vigilância Sanitária (Brasil, 2004).

\subsection{Avaliação das condições higiênico-sanitárias de utensílios e mesas do salão de refeições}

\subsubsection{Critérios para amostragem}

Foram coletadas amostras dos utensílios (pratos, bandejas e talheres) e das mesas do salão de refeições. Tanto os utensílios quanto as mesas eram higienizados pelos auxiliares de serviços gerais (ASG), conforme o procedimento de higienização adotado no serviço de alimentação. As amostras dos utensílios e das mesas foram coletadas durante 8 (oito) dias sendo: dias 1 e 2 - destinados à coleta das amostras dos pratos; dias 3 e 4 - das bandejas; dias 5 e 6 - dos talheres; dias 7 e 8 - mesas. A fim de verificar se houve alteração na contagem de microrganismos sobre as superfícies, as coletas ocorreram nos seguintes horários: antes da abertura do $\mathrm{SA}$, às $10 \mathrm{~h} 00$; durante a distribuição das refeições, às $12 \mathrm{~h} 00$, e próximo ao fechamento do SA, às $14 \mathrm{~h} 00$, ou seja, ao longo do horário de funcionamento do restaurante.

As amostras dos utensílios que foram coletadas às $10 \mathrm{~h} 00$ haviam sido higienizadas ao final do expediente, no dia anterior à coleta. As amostras dos utensílios obtidas às $12 \mathrm{~h} 00$ e $14 \mathrm{~h} 00$, assim como as amostras das mesas obtidas às $10 \mathrm{~h} 00,12 \mathrm{~h} 00 \mathrm{e} 14 \mathrm{~h} 00$, foram coletadas logo após a higienização pelos ASG. No momento da coleta, os utensílios estavam expostos sobre o balcão de distribuição. 


\subsubsection{Técnica de coleta das amostras}

Para os utensílios, utilizou-se a técnica de lavagem de superfície com $50 \mathrm{~mL}$ de solução salina estéril a $0,85 \%(\mathrm{p} / \mathrm{v})$, sendo utilizados os neutralizantes de produtos saneantes, tiossulfato de sódio $1,0 \%(\mathrm{p} / \mathrm{v})$ e Tween-80 0,1\% (v/v) (Evancho et al., 2001). A área aproximada de cada utensílio foi calculada e o resultado foi apresentado em centímetros quadrados $\left(\mathrm{cm}^{2}\right)$. As amostras das mesas foram coletadas pelo método de esfregaço em superfície com swab, sendo diluídas em $10 \mathrm{~mL}$ de solução salina estéril. Para a coleta, foi utilizado molde estéril com área de $100 \mathrm{~cm}^{2}$ (Evancho et al., 2001). As amostras foram acondicionadas em caixas térmicas refrigeradas e transportadas para análise no Laboratório de Microbiologia de Alimentos. As análises microbiológicas foram realizadas no mesmo dia em que as amostras foram coletadas.

\subsubsection{Análise microbiológica utilizando método dependente de cultivo}

Em cada horário de análise, foram coletadas cinco amostras das superfícies dos utensílios e seis amostras das mesas, totalizando, respectivamente, 15 e 18 amostras, por dia. Ao todo, foram analisadas 126 amostras sendo: 30 provenientes dos pratos, 30 das bandejas, 30 dos talheres e 36 das mesas.

Foram pesquisados fungos, bactérias aeróbias heterotróficas mesófilas totais, Staphylococcus aureus, coliformes termotolerantes e a presença de Escherichia coli, segundo os métodos descritos por Evancho et al. (2001). Os resultados obtidos foram expressos em unidades formadoras de colônias por centímetro quadrado $\left(\mathrm{UFC} / \mathrm{cm}^{2}\right)$. Para a enumeração de coliformes, os resultados foram expressos em número mais provável por centímetro quadrado $\left(\mathrm{NMP} / \mathrm{cm}^{2}\right)$, conforme descrito pela American Public Health Association (APHA) (Kornacki \& Johnson, 2001). Staphylococcus aureus American, Type Culture Collection (ATCC) 25923 e E. coli, ATCC 25922, foram utilizados como estirpes de controle.

\subsubsection{Análise dos resultados}

Os resultados obtidos pelo método dependente de cultivo foram comparados com as recomendações sugeridas por Evancho et al. (2001) e Silva Junior (2007). De acordo com a APHA, as superfícies devem ser consideradas em condições higiênico-sanitárias adequadas quando apresentarem contagens de até $2 \mathrm{UFC} / \mathrm{cm}^{2}$ para bactérias aeróbias heterotróficas mesófilas totais (Evancho et al., 2001). Silva Junior (2007) sugere, para os utensílios de mesa (talheres, pratos e bandejas), contagens de até $10^{2} \mathrm{UFC} / \mathrm{cm}^{2}$, para bactérias aeróbias heterotróficas mesófilas totais. Como Evancho et al. (2001) e Silva Junior (2007) não sugerem contagens para fungos, no presente estudo, foi utilizado o mesmo critério empregado para bactérias aeróbias heterotróficas mesófilas totais.

Com relação aos coliformes termotolerantes e S. aureus, Silva Junior (2007) recomenda ausência em $50 \mathrm{~cm}^{2}$ das superfícies de equipamentos e utensílios de preparação (conchas, escumadeiras, entre outros). Esta recomendação foi considerada para os utensílios e mesas, no presente estudo.

Os resultados obtidos foram tabulados no software IBM SPSS Statistic 20 (SPSS Inc, Chicago). Foi realizado o teste de Kolmogorov-Smirnov para verificar a hipótese nula de que os dados das variáveis estudadas originaram de uma distribuição normal. Foi realizado o teste Kruskal-Wallis para dados não paramétricos, seguido do teste de comparações múltiplas, sendo considerado o nível de significância de 5\%. Estes testes foram realizados para avaliar a hipótese nula de que não existia diferença estatisticamente significativa entre as contagens dos microrganismos às $10 \mathrm{~h} 00,12 \mathrm{~h} 00 \mathrm{e} 14 \mathrm{~h} 00$, para uma mesma superfície analisada, nos dois dias de coleta.

\subsection{Avaliação do perfil da comunidade microbiana sobre as superfícies analisadas por método independente de cultivo}

Foram analisadas 36 amostras, sendo: nove provenientes dos pratos, nove das bandejas, nove dos talheres e nove das mesas, coletadas às $10 \mathrm{~h} 00$, a fim de verificar a comunidade microbiana presente nas superfícies. A técnica de coleta e a origem das amostras utilizadas nas análises por métodos independentes de cultivo foram as mesmas empregadas nos métodos dependentes de cultivo.

A avaliação do perfil da comunidade microbiana foi realizada por reação em cadeia de polimerase (Polymerase Chain Reaction - PCR), separados por eletroforese em gel de gradiente desnaturante (Denaturing 
Gradient Gel Electrophoresis - DGGE). Para a extração de DNA, $3 \mathrm{~mL}$ da água de lavagem das mesas e dos swabs das amostras originais das superfícies foram removidos e filtrados em membrana de nitrocelulose com poros de 0,22 $\mu \mathrm{m}$ (Sartorius, Gottingen, Alemanha) (Heuer \& Smalla, 1997).

A extração do DNA total foi realizada utilizando-se o FastDNA® SPIN Kit for Soil (MP Biomedicals, Solon, EUA), seguindo as recomendações do fabricante, e foram criopreservados a $-20{ }^{\circ} \mathrm{C}$. Para a avaliação da estrutura da comunidade bacteriana total, foi utilizado o par de iniciadores U968 $f$ GC (5'AACGCGAAGAACCTTAC-3') e L1401 $r$ (5'-GCGTGTGTACAAGACCC-3'), para amplificar as regiões V6-V8, que codificam a subunidade 16S do RNA ribossomal (Heuer \& Smalla, 1997). Os fragmentos da PCR foram separados por DGGE utilizando o equipamento Dcode ${ }^{\mathrm{TM}}$ Universal Mutation Detection System (Bio-Rad, Richmond, California, EUA) (Muyzer et al., 1993). Os géis de DGGE (ureia e formamida entre 45 e $65 \%)$ foram preparados com poliacrilamida (6\%) e solução de Tris-acetato ( $\mathrm{pH} 8,3$ ).

A eletroforese foi realizada com solução de Tris-acetato-EDTA a $60{ }^{\circ} \mathrm{C}$ em voltagem constante de $75 \mathrm{~V}$, por 16 horas. Os géis de DGGE foram corados com SybrGreen ${ }^{\circledR}$ (Molecular Probes, Oregon, EUA) e digitalizados com o auxílio do equipamento Storm ${ }^{\circledR}$ (GE Healthcare), utilizando o programa Bionumerics v 6.5 (Applied Maths), seguindo as instruções do fabricante.

Os perfis das bandas foram analisados e convertidos em matrizes numéricas quantitativas com o programa Bionumerics v 6.5, seguindo as instruções do fabricante. As bandas que apresentavam maior densidade no gel de eletroforese e aquelas presentes em todas as superfícies analisadas, ou seja, que indicavam os microrganismos amplamente distribuídos nas superfícies, foram selecionadas e excisadas do gel de poliacrilamida. Estas bandas foram submetidas ao sequenciamento da região que codifica a subunidade $16 \mathrm{~S}$ do RNA ribossomal na empresa Macrogen (Seoul, Coreia). Os resultados obtidos foram comparados com a sequência de genes depositadas no GenBank.

Para identificar a quantidade dos possíveis microrganismos nas amostras e verificar se houve diferença estatisticamente significativa entre os números de bandas obtidos por PCR-DGGE para cada superfície, foi realizado o teste de Kruskal-Wallis e o cálculo da mediana pelo teste de Kolmogorov-Smirnov. Utilizou-se o pacote do programa no software IBM SPSS Statistic 20 (SPSS Inc, Chicago).

\section{Resultados e discussão}

No serviço de alimentação em estudo, as mesas do salão de refeições eram higienizadas manualmente pelos ASG, sendo utilizado pano umedecido com hipoclorito de sódio a 100 ppm (v/v). Os utensílios (pratos, bandejas e talheres) eram pré-lavados em água corrente, com o auxílio de esponja para remover os resíduos de alimentos. Em seguida, os utensílios eram colocados na máquina de lavar, lavados com detergente neutro a $40{ }^{\circ} \mathrm{C}$ e secos a $60^{\circ} \mathrm{C}$.

Ainda que a Resolução (RDC) n. ${ }^{\circ}$ 216/2004 da Agência Nacional de Vigilância Sanitária (ANVISA) (Brasil, 2004) não estabeleça os parâmetros de temperatura para a higienização de superfícies, o Centers for Diseases Control (Centers for Disease Control and Prevention, 2013) recomenda que a temperatura de água de lavagem deve estar entre 66 e $74{ }^{\circ} \mathrm{C}$, e a de secagem, a $71{ }^{\circ} \mathrm{C}$. Mattick et al. (2003) sugerem que a temperatura da água de lavagem seja superior a $40{ }^{\circ} \mathrm{C}$, para reduzir a contagem de microrganismos sobre as superfícies. No presente estudo, as temperaturas observadas estavam abaixo do preconizado pelo CDC (Centers for Disease Control and Prevention, 2013).

Resultado semelhante foi obtido por Chatt et al. (2017), que também verificaram inadequação na temperatura da água de lavagem. Os autores observaram que a água estava a $56{ }^{\circ} \mathrm{C}$, além de detectarem a presença de resíduos de alimentos no interior da máquina de lavar. De acordo com Chatt et al. (2017), as não conformidades identificadas sugerem que os utensílios podem ser fonte de contaminação no estabelecimento. 
No presente estudo, ao final do processo de higienização, os utensílios ainda estavam úmidos e apresentavam resíduos de alimentos, o que pode favorecer a multiplicação e a sobrevivência de microrganismos sobre os mesmos. Apesar de os utensílios não estarem visualmente limpos, os ASG davam continuidade ao processo de higienização aspergindo álcool 70\%.

A presença de resíduos alimentares nos utensílios indica que o processo de higienização adotado no serviço de alimentação está em desacordo com a legislação vigente, que estabelece que as superfícies das instalações, equipamentos e utensílios devem estar em condições higiênico-sanitárias adequadas e livres de sujidades (Brasil, 2004).

As não conformidades identificadas durante o processo de higienização foram confirmadas pelas análises microbiológicas, que evidenciaram que 100 e $80 \%$ das amostras dos utensílios e das mesas, respectivamente, estavam acima das recomendações sugeridas por Silva Junior (2007) e Evancho et al. (2001) para contagem de bactérias aeróbias heterotróficas mesófilas totais e fungos.

As amostras dos utensílios, que foram coletadas às $10 \mathrm{~h} 00$ (antes da abertura do serviço de alimentação), apresentaram as maiores contagens para bactérias aeróbias heterotróficas mesófilas totais, entre $1,4 \times 10^{7} \mathrm{e}$ $2,0 \times 10^{9} \mathrm{UFC} / \mathrm{cm}^{2}$, e também para fungos, cujas contagens estavam entre $3,0 \times 10^{3} \mathrm{e} 2,6 \times 10^{5} \mathrm{UFC} / \mathrm{cm}^{2}$. Essas amostras haviam sido higienizadas, na máquina de lavar, ao final do expediente, no dia anterior à coleta, e ficaram expostas sobre o balcão de distribuição. Os resultados sugerem que o contato da microbiota presente nas superfícies com os resíduos de alimentos e a umidade tenham favorecido as altas contagens observadas às $10 \mathrm{~h} 00$.

Ao longo do dia, foi observada redução na contagem microbiana, havendo diferença estatisticamente significativa para a contagem de bactérias aeróbias heterotróficas mesófilas totais, nas amostras dos pratos (Dia 1: p-valor 0,02 e Dia 2: p-valor 0,04) e dos talheres (Dia 3: p-valor 0,002 e Dia 4: p-valor 0,008). Também houve diferença estatisticamente significativa para a contagem de fungos (Dia 4: p-valor 0,027) e para a enumeração de coliformes termotolerantes (Dias 3 e 4: p-valor 0,005), nas amostras dos talheres (Tabela 1). Embora, ao longo do dia, tenha ocorrido redução na contagem desses microrganismos, as amostras permaneceram em condições higiênico-sanitárias inadequadas, podendo as mesmas ser fonte de contaminação no estabelecimento. 
Tabela 1. Contagens microbianas das amostras obtidas dos utensílios e das mesas durante o funcionamento do serviço de alimentação.

\begin{tabular}{|c|c|c|c|c|c|c|c|c|c|c|c|c|c|}
\hline \multirow{3}{*}{ 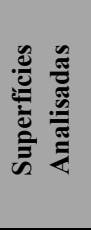 } & \multirow{3}{*}{ 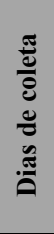 } & \multicolumn{4}{|c|}{$\begin{array}{c}\text { Bactérias Mesófilas } \\
\left(\mathrm{UFC} / \mathrm{cm}^{2}\right)^{\mathrm{a}}\end{array}$} & \multicolumn{4}{|c|}{$\begin{array}{c}\text { Fungos e leveduras } \\
\left(\mathrm{UFC} / \mathbf{c m}^{2}\right)\end{array}$} & \multicolumn{4}{|c|}{$\begin{array}{c}\text { Coliformes termotolerantes } \\
\left(\mathrm{NMP} / \mathrm{cm}^{2}\right)^{\mathbf{b}}\end{array}$} \\
\hline & & $10 \mathrm{~h}$ & $12 \mathrm{~h}$ & $14 \mathrm{~h}$ & \multirow{2}{*}{ 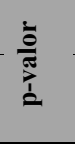 } & $10 \mathrm{~h}$ & $12 \mathrm{~h}$ & $14 \mathrm{~h}$ & \multirow{2}{*}{$\frac{\grave{a}}{\pi}$} & $10 \mathrm{~h}$ & $12 \mathrm{~h}$ & $14 \mathrm{~h}$ & \multirow{2}{*}{ 产 } \\
\hline & & & $\begin{array}{c}\text { Mediana } \\
\text { (mínimo-máximo) }\end{array}$ & & & & $\begin{array}{c}\text { Mediana } \\
\text { (mínimo-máximo) } \\
\end{array}$ & & & & $\begin{array}{c}\text { Mediana } \\
\text { (mínimo-máximo) } \\
\end{array}$ & & \\
\hline \multirow{2}{*}{ Pratos } & 1 & $\begin{array}{c}2,0 \times 10^{8 \mathrm{~A}} \\
\left(1,3 \times 10^{8}-3,3 \times 10^{8}\right)\end{array}$ & $\begin{array}{c}1,6 \times 10^{7 \mathrm{AB}} \\
\left(1,4 \times 10^{6}-4,2 \times 10^{8}\right)\end{array}$ & $\begin{array}{c}5,0 \times 10^{3 \mathrm{~B}} \\
\left(5,0 \times 10^{3}-2,9 \times 10^{7}\right)\end{array}$ & 0,02 & $\begin{array}{c}1,4 \times 10^{5} \\
\left(5,0 \times 10^{3}-2,4 \times 10^{5}\right)\end{array}$ & $\begin{array}{c}2,0 \times 10^{5} \\
\left(5,0 \times 10^{3}-1,1 \times 10^{8}\right)\end{array}$ & $\begin{array}{c}5,0 \times 10^{4} \\
\left(5,0 \times 10-8,5 \times 10^{4}\right)\end{array}$ & 0,153 & $\begin{array}{c}5,5 \times 10^{4} \\
\left(4,7 \times 10^{3-5} 5 \times 10^{4}\right)\end{array}$ & $\begin{array}{c}2,3 \times 10^{4} \\
\left(1,5 \times 10^{3}-5,5 \times 10^{4}\right)\end{array}$ & $\begin{array}{c}4,7 \times 10^{3} \\
\left(3,6 \times 10^{2}-1,5 \times 10^{4}\right)\end{array}$ & 0,082 \\
\hline & 2 & $\begin{array}{c}3,4 \times 10^{8 A} \\
\left(1,6 \times 10^{8}-2,0 \times 10^{9}\right)\end{array}$ & $\begin{array}{c}3,4 \times 10^{7 \mathrm{~B}} \\
\left(1,2 \times 10^{6}-3,4 \times 10^{8}\right)\end{array}$ & $\begin{array}{c}8,3 \times 10^{7 \mathrm{~B}} \\
\left(5,0 \times 10^{3}-3,4 \times 10^{8}\right)\end{array}$ & 0,04 & $\begin{array}{c}2,0 \times 10^{5} \\
\left(1,0 \times 10^{5}-2,7 \times 10^{6}\right)\end{array}$ & $\begin{array}{c}1,4 \times 10^{5} \\
\left(5,0 \times 10^{3}-3,4 \times 10^{5}\right)\end{array}$ & $\begin{array}{c}1,7 \times 10^{4} \\
\left(5,0 \times 10^{2}-5,0 \times 10^{5}\right)\end{array}$ & 0,124 & $\begin{array}{c}5,5 \times 10^{4} \\
\left(1,5 \times 10^{4}-5,5 \times 10^{4}\right)\end{array}$ & $\begin{array}{c}5,5 \times 10^{4} \\
\left(4,7 \times 10^{2}-5,5 \times 10^{4}\right)\end{array}$ & $\begin{array}{c}2,7 \times 10^{3} \\
\left(3,6 \times 10^{2}-5,5 \times 10^{4}\right)\end{array}$ & 0,476 \\
\hline \multirow{2}{*}{ Talheres } & 3 & $\begin{array}{c}9,0 \times 10^{6 \mathrm{~A}} \\
\left(6,5 \times 10^{6}-2,0 \times 10^{7}\right)\end{array}$ & $\begin{array}{c}1,5 \times 10^{4 \mathrm{~B}} \\
\left(1,3 \times 10^{4}-2,5 \times 10^{4}\right)\end{array}$ & $\begin{array}{c}5,5 \times 10^{4 B} \\
\left(4,4 \times 10^{4}-2,0 \times 10^{5}\right)\end{array}$ & 0,002 & $\begin{array}{c}3,0 \times 10^{3} \\
\left(5,5 \times 10^{5}-1,4 \times 10^{7}\right)\end{array}$ & $\begin{array}{c}3,4 \times 10^{4} \\
\left(2,7 \times 10^{4}-5,0 \times 10^{4}\right)\end{array}$ & $\begin{array}{c}2,3 \times 10^{4} \\
\left(2,5 \times 10^{3}-8,5 \times 10^{4}\right)\end{array}$ & 0,247 & $\begin{array}{c}1,5 \times 10^{4 \mathrm{~A}} \\
\left(1,1 \times 10^{4}-5,5 \times 10^{4}\right)\end{array}$ & $\begin{array}{c}1,5 \times 10^{2 \mathrm{~B}} \\
\left(1,5 \times 10^{2}-4,6 \times 10^{2}\right)\end{array}$ & $\begin{array}{c}1,5 \times 10^{2 \mathrm{~B}} \\
\left(1,5 \times 10^{2}-4,6 \times 10^{2}\right)\end{array}$ & 0,005 \\
\hline & 4 & $\begin{array}{c}4,7 \times 10^{6 \mathrm{~A}} \\
\left(5,5 \times 10^{5}-1,4 \times 10^{7}\right)\end{array}$ & $\begin{array}{c}1,7 \times 10^{4 \mathrm{~B}} \\
\left(8,5 \times 10^{3}-4,5 \times 10^{5}\right)\end{array}$ & $\begin{array}{c}1,3 \times 10^{4 \mathrm{~B}} \\
\left(5,0 \times 10^{2}-1,2 \times 10^{5}\right)\end{array}$ & 0,008 & $\begin{array}{c}8,5,0 \times 10^{4 \mathrm{~B}} \\
\left(3,7 \times 10^{4}-1,6 \times 10^{5}\right)\end{array}$ & $\begin{array}{c}7,5 \times 10^{4 \mathrm{AB}} \\
\left(5,0 \times 10^{2}-3,8 \times 10^{5}\right)\end{array}$ & $\begin{array}{c}5,0 \times 10^{2 \mathrm{~A}} \\
\left(5,0 \times 10^{2}-5,0 \times 10^{2}\right)\end{array}$ & 0,027 & $\begin{array}{c}5,5 \times 10^{4 \mathrm{~A}} \\
\left(2,3 \times 10^{4}-5,5 \times 10^{4}\right)\end{array}$ & $\begin{array}{c}1,5 \times 10^{2 B} \\
\left(1,5 \times 10^{2}-4,6 \times 10^{2}\right)\end{array}$ & $\begin{array}{c}1,8 \times 10^{2 \mathrm{~B}} \\
\left(1,5 \times 10^{2}-1,2 \times 10^{3}\right)\end{array}$ & 0,005 \\
\hline \multirow{2}{*}{ Bandejas } & 5 & $\begin{array}{c}7,5 \times 10^{7} \\
\left(2,9 \times 10^{7}-4,5 \times 10^{8}\right)\end{array}$ & $\begin{array}{c}2,6 \times 10^{8} \\
\left(2,8 \times 10^{7}-2,6 \times 10^{8}\right)\end{array}$ & $\begin{array}{c}2,8 \times 10^{8} \\
\left(4,3 \times 10^{7}-5,0 \times 10^{8}\right)\end{array}$ & 0,681 & $\begin{array}{c}2,6 \times 10^{6} \\
\left(1,4 \times 10^{6}-3,3 \times 10^{7}\right)\end{array}$ & $\begin{array}{c}1,5 \times 10^{6} \\
\left(4,1 \times 10^{5}-3,1 \times 10^{6}\right)\end{array}$ & $\begin{array}{c}1,5 \times 10^{6} \\
\left(5,5 \times 10^{5}-1,5 \times 10^{6}\right)\end{array}$ & 0,168 & $\begin{array}{c}4,7 \times 10^{4} \\
\left(1,5 \times 10^{4}-5,5 \times 10^{4}\right)\end{array}$ & $\begin{array}{c}5,5 \times 10^{4} \\
\left(1,2 \times 10^{3}-5,5 \times 10^{4}\right)\end{array}$ & $\begin{array}{c}5,4 \times 10^{4} \\
\left(2,3 \times 10^{3}-5,5 \times 10^{4}\right)\end{array}$ & 0,708 \\
\hline & 6 & $\begin{array}{c}1,5 \times 10^{8} \\
\left(1,0 \times 10^{7}-3,9 \times 10^{8}\right)\end{array}$ & $\begin{array}{c}9,0 \times 10^{7} \\
\left(2,5 \times 10^{7}-8,5 \times 10^{8}\right)\end{array}$ & $\begin{array}{c}2,4 \times 10^{8} \\
\left(1,5 \times 10^{8}-3,0 \times 10^{8}\right)\end{array}$ & 0,716 & $\begin{array}{c}1,0 \times 10^{6} \\
\left(2,4 \times 10^{5}-1,7 \times 10^{6}\right)\end{array}$ & $\begin{array}{c}8,5 \times 10^{5} \\
\left(5,0 \times 10^{2}-1,9 \times 10^{6}\right)\end{array}$ & $\begin{array}{c}4,2 \times 10^{5} \\
\left(5,0 \times 10^{2}-3,0 \times 10^{6}\right)\end{array}$ & 0,845 & $\begin{array}{c}5,5 \times 10^{4} \\
\left(5,5 \times 10^{4}-5,5 \times 10^{4}\right)\end{array}$ & $\begin{array}{c}5,5 \times 10^{4} \\
\left(5,5 \times 10^{4}-5,5 \times 10^{4}\right)\end{array}$ & $\begin{array}{c}5,5 \times 10^{4} \\
\left(1,8 \times 10^{3}-5,5 \times 10^{4}\right)\end{array}$ & 0,368 \\
\hline \multirow[b]{2}{*}{ Mesas } & 7 & $\begin{array}{c}8,4 \mathrm{X} 10^{2 \mathrm{~A}} \\
\left(1,1 \times 10^{2}-5,1 \times 10^{3}\right)\end{array}$ & $\begin{array}{c}6,1 \times 10^{3 \mathrm{AB}} \\
\left(9,0 \times 10^{2}-6,7 \times 10^{4}\right)\end{array}$ & $\begin{array}{c}2,1 \times 10^{4 \mathrm{~B}} \\
\left(3,5 \times 10^{3}-3,2 \times 10^{4}\right)\end{array}$ & 0,011 & $\begin{array}{c}1,3 \times 10^{4 \mathrm{~A}} \\
\left(4,0 \times 10^{3}-1,5 \times 10^{5}\right)\end{array}$ & $\begin{array}{c}1,5 \times 10^{5 \mathrm{~B}} \\
\left(2,9 \times 10^{4}-7,6 \times 10^{5}\right)\end{array}$ & $\begin{array}{c}3,8 \times 10^{4 \mathrm{~A}} \\
\left(2,8 \times 10^{4}-6,3 \times 10^{4}\right)\end{array}$ & 0,023 & $\begin{array}{c}2,4 \times 10^{2} \\
\left(3,6 \times 10-1,1 \times 10^{3}\right)\end{array}$ & $\begin{array}{c}7,8 \times 10^{2} \\
\left(4,3 \times 10^{1}-1,1 \times 10^{3}\right)\end{array}$ & $\begin{array}{c}6,8 \times 10 \\
\left(3,0 \times 10-4,6 \times 10^{2}\right)\end{array}$ & 0,110 \\
\hline & 8 & $\begin{array}{c}1,1 \mathrm{X} 10^{3} \\
\left(1,0 \times 10^{1}-4,6 \times 10^{5}\right)\end{array}$ & $\begin{array}{c}3,1 \times 10^{4} \\
\left(1,0 \times 10^{3}-2,0 \times 10^{6}\right)\end{array}$ & $\begin{array}{c}8,5 \times 10^{3} \\
\left(6,3 \times 10^{2}-3,0 \times 10^{4}\right)\end{array}$ & 0,108 & $\begin{array}{c}5,3 \times 10 \\
\left(3,7 \times 10^{1}-9,0 \times 10^{2}\right)\end{array}$ & $\begin{array}{c}1,0 \times 10^{2} \\
\left(1,0 \times 10^{1}-3,2 \times 10^{3}\right)\end{array}$ & $\begin{array}{c}5,7 \times 10 \\
\left(1,7 \times 10^{1}-2,2 \times 10^{2}\right)\end{array}$ & 0,931 & $\begin{array}{c}6,6 \\
\left(2,0 \times 10^{1}-9,1 \times 10\right)\end{array}$ & $\begin{array}{c}92 \\
\left(3,6 \times 10^{1}-4,6 \times 10^{2}\right)\end{array}$ & $\begin{array}{c}3,0 \\
\left(3,0 \times 10-4,6 \times 10^{2}\right)\end{array}$ & 0,281 \\
\hline
\end{tabular}


Com relação aos dias de coleta das amostras das mesas (dias 7 e 8), as amostras obtidas às $10 \mathrm{~h} 00$ apresentaram contagens para bactérias aeróbias heterotróficas mesófilas totais entre $1,1 \times 10$ e 4,6×10 $\mathrm{UFC} / \mathrm{cm}^{2}$.

Ao longo do dia 7, houve aumento na contagem dos microrganismos sobre as mesas com diferença estatisticamente significativa para as contagens de bactérias mesófilas ( $p$-valor 0,011 ) (Tabela 1). O aumento na contagem microbiana pode estar relacionado com a alta rotatividade dos comensais, uma vez que eram atendidas cerca 3.500 pessoas por dia, das $10 \mathrm{~h} 00$ às $14 \mathrm{~h} 00$, o que poderia dificultar a higienização adequada das mesas durante o funcionamento do restaurante.

Medeiros et al. (2017) também identificaram altas contagens de bactérias aeróbias heterotróficas mesófilas totais em superfícies de manipulação de alimentos, assim como em utensílios (cuba de inox e espátula de cocção). A contagem de bactérias aeróbias heterotróficas mesófilas totais não está diretamente relacionada com a presença de patógenos, mas é comumente utilizada como indicador de qualidade (Møretrø \& Langsrud, 2017). Altas contagens desses microrganismos sobre as superfícies indicam que houve inadequação nos procedimentos de limpeza e sanitização (Silva et al., 2014; Møretrø \& Langsrud, 2017).

Gkana et al. (2016) colocam que as superfícies que possuem elevadas contagens de microrganismos podem ser fonte de contaminação dos alimentos, nos serviços de alimentação.

Com relação à enumeração de coliformes termotolerantes, cuja presença está relacionada à contaminação de origem fecal, $100 \%$ dos utensílios e das mesas apresentaram contagens acima do limite recomendado por Silva Junior (2007). Os pratos, bandejas e talheres apresentaram contaminação por E. coli. Pelo método independente de cultivo, foi detectada a presença de Citrobacter sp. sobre as mesas e Klebsiella sp. em todas as superfícies analisadas.

E. coli e Klebsiella sp. também foram detectadas por Jerônimo et al. (2011), Rezende et al. (2012) e Silva et al. (2014) sobre superfícies dos pratos, talheres, esponjas, placas de corte e pia da cozinha, e na área de pré-preparo e preparo de alimentos. A presença de E. coli pode estar associada à contaminação de origem fecal e também com a contaminação indireta proveniente do ambiente (Leclerc et al., 2001; Silva et al., 2006). Citrobacter sp. e Klebsiella sp. são frequentemente enumerados como coliformes termotolerantes. Além de apresentarem como habitat o intestino, esses microrganismos também podem ser naturalmente encontrados no ambiente, o que não assegura completamente a sua associação com contaminação fecal (Leclerc et al., 2001; Silva et al., 2006).

A detecção de coliformes termotolerantes nas superfícies analisadas pode ser uma consequência da inadequação do processo de higienização. Neste processo, normalmente são empregados métodos físicos, como o calor, e químicos, que resultam na redução dos microrganismos de interesse em Saúde Pública a níveis seguros (Brasil, 2004). Entretanto, no presente estudo, foram observadas falhas nos procedimentos empregados, como a baixa temperatura da água de lavagem e de secagem, além da possibilidade de disseminação destes microrganismos sobre as superfícies, devido ao uso de esponjas para limpeza prévia. Wolde \& Bacha (2016) colocam que as esponjas podem apresentar resíduos de alimentos, favorecendo a multiplicação de microrganismos e a contaminação dos utensílios.

S. aureus não foi detectado em nenhuma amostra dos utensílios, mas esteve presente em $100 \%$ das amostras das mesas. As contagens variaram de $1,0 \times 10$ a 2,5 $\times 10^{4} \mathrm{UFC} / \mathrm{cm}^{2}$, ao longo do funcionamento do serviço de alimentação. Ainda que todas as amostras analisadas estivessem com contagens acima do recomendado por Silva Junior (2007), aquelas que foram coletadas às $10 \mathrm{~h} 00$ apresentaram menores contagens. Este resultado pode estar relacionado ao fato de que, no horário desta coleta, o restaurante ainda não estava em funcionamento.

No presente estudo, os comensais podem ter sido a fonte de contaminação das mesas do salão de refeições por $S$. aureus. Este microrganismo é comumente encontrado na pele e mucosas do trato respiratório, constituindo-se em fonte de contaminação para os alimentos e superfícies (Castro et al., 2016). 
A presença de $S$. aureus sobre as mesas, mesmo antes da abertura do serviço de alimentação, pode estar relacionada com a capacidade de esse microrganismo sobreviver em ambientes secos, como as superfícies inanimadas e a pele, podendo permanecer viável por mais de 90 dias em superfícies de polietileno, após o contato inicial (Neely \& Maley, 2000; Kusumaningrum et al., 2002; Chaibenjawong \& Foster, 2011; Hennekinne et al., 2012).

S. aureus, assim como Salmonella spp. e E. coli, são os principais agentes envolvidos nos surtos de DTA (Brasil, 2017). No Brasil, os registros apontam que os surtos DTA ocorrem principalmente nos serviços de alimentação devido à manipulação inadequada dos alimentos e à higienização deficiente dos equipamentos, alimentos e utensílios (Oliveira et al., 2010; Losasso et al., 2012). Além disso, S. aureus é um patógeno oportunista, que pode causar desde infecções superficiais na pele até doenças invasivas graves e potencialmente fatais (Chaibenjawong \& Foster, 2011; Hennekinne et al., 2012).

Os resultados obtidos pelas análises microbiológicas por métodos independentes de cultivo mostraram que houve diferença estatisticamente significativa $(\mathrm{p}<0,05)$ entre os números de bandas presentes nos utensílios e nas mesas do salão de refeições (Figura 1). Os utensílios que foram lavados na máquina de lavar apresentaram maior número de bandas do que as mesas do salão de refeições que foram higienizadas manualmente (Figura 1).
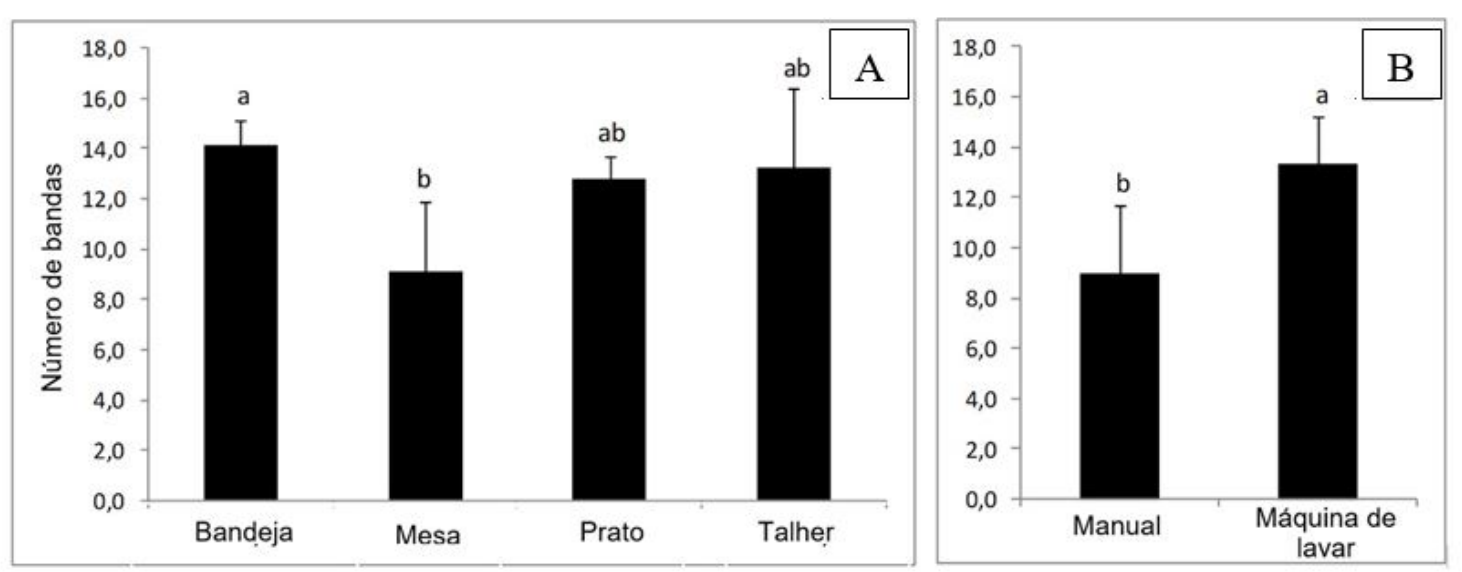

Figura 1. Número de bandas obtidas por reação em cadeia de polimerase separadas por denaturing gradient gel electrophoresis (PCR-DGGE). Nota: Grupos de análise: (A) superfície analisada e (B) método de higienização empregado; Letras diferentes em um mesmo grupo de análise diferem estatisticamente no nível de significância de 5\%, ao teste de Kurskal-Wallis.

Esses resultados reforçam a inadequação do processo de higienização e que a máquina de lavar pode ser uma fonte potencial de contaminação, no serviço de alimentação em estudo.

Foram selecionadas, para identificação por sequenciamento da região que codifica a subunidade $16 \mathrm{~S}$ do rRNA, as bandas presentes em todas as superfícies analisadas - que indicavam os microrganismos amplamente distribuídos - e aquelas que apresentavam maior densidade no gel de eletroforese. As bandas de maior densidade foram relacionadas a um maior número de cópias do rRNA e, possivelmente, um maior número do microrganismo identificado na superfície analisada (Figura 2). 


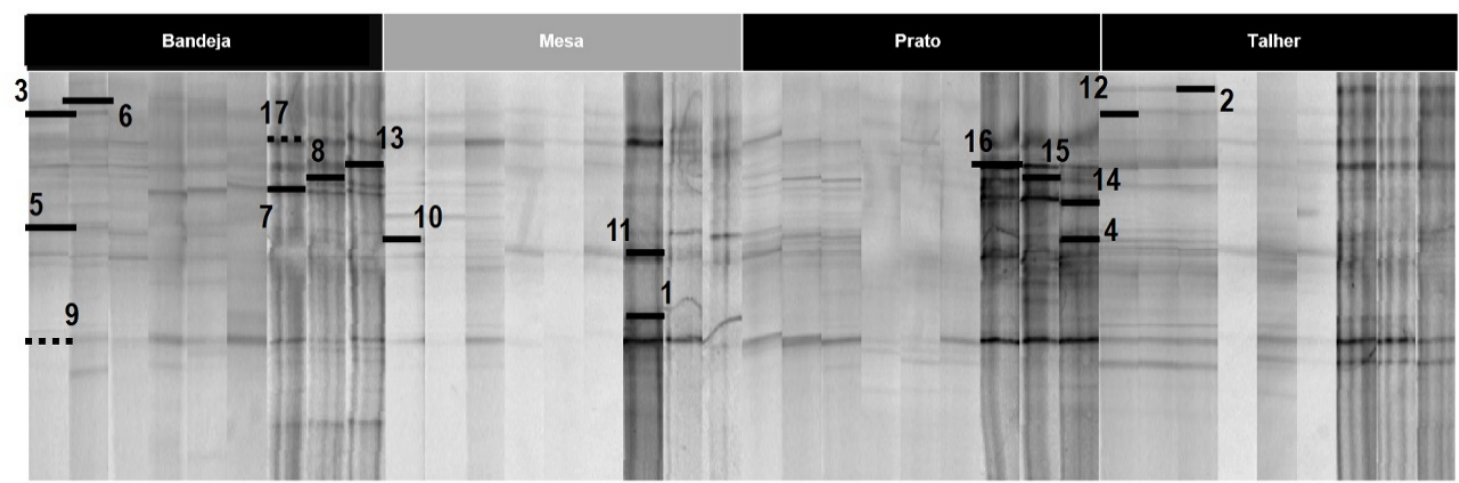

Figura 2. Perfis de bandas de $16 \mathrm{~S}$ rRNA obtidas por reação em cadeia de polimerase separados por denaturing gradient gel electrophoresis (PCR-DGGE) das amostras dos utensílios e das mesas. As linhas pretas indicam as bandas selecionadas para o sequenciamento. As bandas marcadas com linhas pretas pontilhadas estavam presentes em todas as amostras.

O crescente emprego da técnica de sequenciamento da região que codifica a subunidade $16 \mathrm{~S}$ do rRNA para identificar microrganismos tem favorecido a detecção de grupos microbianos (cultiváveis ou não cultiváveis) importantes, em ambientes de processamento de alimentos (Møretrø \& Langsrud, 2017). Como vantagens, esta técnica não requer o emprego de neutralizantes de desinfetantes no meio de cultura e não depende de variáveis, como o controle do tempo, da temperatura, da atmosfera ou de fatores nutricionais para a multiplicação dos microrganismos (Møretrø \& Langsrud, 2017).

Pelo método independente de cultivo, além de Klebsiella sp., também foi verificado que microrganismos pertencentes ao gênero Acinetobacter sp. estavam em todas as superfícies analisadas. Micrococcus luteus foi detectado nas bandejas e Aeromonas cavie e A. hydrophilla, nos talheres (Tabela 2).

Tabela 2. Identificação das bandas obtidas por reação em cadeia de polimerase separadas por denaturing gradient gel electrophoresis (PCR-DGGE), tomando por base o BLAST (GenBank), utilizando iniciadores universais para bactéria total.

\begin{tabular}{|c|c|c|c|c|c|}
\hline Banda & Origem & Microrganismos & $\begin{array}{c}\text { Percentual de } \\
\text { similaridade } \\
(\%)\end{array}$ & $\begin{array}{l}\text { Número de } \\
\text { acesso no } \\
\text { GenBank }\end{array}$ & $\begin{array}{c}\text { Número de } \\
\text { bases } \\
\text { analisadas } \\
\text { (bp) }\end{array}$ \\
\hline 1 & Mesa & Klebsiella pneumoniae & 100 & JN969334 & 361 \\
\hline 2 & Talher & Aeromonas caviae & 100 & JF920476 & 385 \\
\hline 3 & Bandeja & Micrococcus luteus & 99 & JX262404 & 345 \\
\hline 4 & Prato & $\begin{array}{c}\text { Acinetobacter calcoaceticus } \\
\text { subsp. anitratus }\end{array}$ & 99 & AB302132 & 471 \\
\hline 5 & Bandeja & Micrococcus luteus & 99 & JX262404 & 387 \\
\hline 6 & Bandeja & Micrococcus luteus & 99 & JX262404 & 405 \\
\hline 7 & Bandeja & Acinetobacter sp. & 99 & JF772529 & 509 \\
\hline 8 & Bandeja & Acinetobacter baumannii & 99 & HE978267 & 405 \\
\hline $9^{*}$ & Utensílios e mesa & Klebsiella sp. & 98 & GQ416644 & 387 \\
\hline 10 & Mesa & Acinetobacter sp. & 98 & AM412161 & 248 \\
\hline
\end{tabular}


Tabela 2. Continuação...

\begin{tabular}{|c|c|c|c|c|c|}
\hline Banda & Origem & Microrganismos & $\begin{array}{c}\text { Percentual de } \\
\text { similaridade } \\
(\%)\end{array}$ & $\begin{array}{l}\text { Número de } \\
\text { acesso no } \\
\text { GenBank }\end{array}$ & $\begin{array}{c}\text { Número de } \\
\text { bases } \\
\text { analisadas } \\
\text { (bp) }\end{array}$ \\
\hline 11 & Mesa & Citrobacter $\mathrm{sp}$ & 98 & HM536988 & 424 \\
\hline 12 & Talher & Aeromonas hydrophila & 98 & JX262991 & 357 \\
\hline 13 & Bandeja & Acinetobacter sp. & 98 & HM366447 & 345 \\
\hline 14 & Prato & $\begin{array}{c}\text { Acinetobacter calcoaceticus } \\
\text { subsp. anitratus }\end{array}$ & 97 & AB302132 & 370 \\
\hline 15 & Prato & Acinetobacter rudis & 97 & FR773879 & 353 \\
\hline 16 & Prato & $\begin{array}{c}\text { Acinetobacter calcoaceticus } \\
\text { subsp. anitratus }\end{array}$ & 97 & AB302132 & 465 \\
\hline $17 *$ & Utensílios e mesa & Acinetobacter sp. & 97 & HM366447 & 317 \\
\hline
\end{tabular}

*Espécies presentes em todas as amostras.

Acinetobacter sp. apresenta grande tolerância às condições variadas de umidade, temperatura e $\mathrm{pH}$, o que favorece sua sobrevivência em superfícies úmidas e secas por períodos prolongados (Peleg et al., 2008). Este microrganismo é comumente encontrado no ambiente e pode estar presente na microbiota da pele humana (Peleg et al., 2008; Scarcella et al., 2016). Acinetobacter sp. já foi isolado em superfícies de processamento de alimentos por Cerveny et al. (2009) e Møretrø \& Langsrud (2017).

Microrganismos do gênero Micrococcus podem ser encontrados no ambiente e na pele, mas assim como Acinetobacter sp. não têm sido relacionados a doenças transmitidas por alimentos (Cohen et al., 2017). Por outro lado, A. calcoaceticus é considerado um importante microrganismo causador de infecções relacionadas à assistência à saúde (Wong et al., 2017).

Outro microrganismo detectado no serviço de alimentação foi $A$. hydrophila, que tem sido isolado de amostras ambientais, do ambiente aquático e de alimentos, como peixe, mariscos, aves e carne crua (Daskalov, 2006). A. hydrophila tem causado surtos de DTA em serviços de alimentação, devido ao consumo de produtos da aquicultura e de alimentos prontos que são mantidos refrigerados (Daskalov, 2006; Zhang et al., 2012). Além disso, A. hydrophila é considerado um patógeno alimentar emergente devido à sua capacidade de crescer sob baixas temperaturas (Adams \& Moss, 2000). No presente estudo, A. hydrophila foi detectado nos talheres, porém a fonte de contaminação por este microrganismo permaneceu inconclusiva, uma vez que este não foi encontrado em outras superfícies do serviço de alimentação, segundo os critérios de seleção das bandas sequenciadas.

\section{Conclusão}

Todas as superfícies analisadas estavam em condições higiênico-sanitárias inadequadas, devido às não conformidades identificadas no processo de higienização, como a ineficiência da máquina de lavar em relação às temperaturas de lavagem e de secagem, e a deficiente remoção de resíduos de alimentos das superfícies.

O processo de higienização manual empregado nas mesas também não se mostrou eficiente, uma vez que elevadas contagens microbianas foram identificadas antes da abertura do serviço de alimentação.

Na microbiota do serviço de alimentação, foi observada a ampla disseminação de microrganismos do grupo dos coliformes e Acinetobacter sp., confirmando a inadequação do processo de higienização. 
Microrganismos patogênicos, como S. aureus e A. hydrophila, foram detectados nas superfícies do serviço de alimentação.

Os achados microbiológicos podem resultar tanto na ocorrência de doenças transmitidas por alimentos quanto de infecções na pele e mucosas dos comensais. Desta forma, é importante adequar o processo de higienização, assim como realizar manutenção da máquina de lavar, a fim de minimizar o risco de contaminação no serviço de alimentação. Também é necessário realizar a capacitação dos ASG para que possam executar de forma adequada os procedimentos de limpeza e sanitização, e auxiliar na detecção de não conformidades.

\section{Agradecimentos}

À Fundação de Amparo à Pesquisa do Estado do Rio de Janeiro (FAPERJ) e à Universidade Federal do Rio de Janeiro.

\section{Referências}

Adams, M. R., \& Moss, M. O. (2000). Food microbiology (2nd ed.). Cambridge: Royal Society of Chemistry.

Alvarez, M. E. (1991). Organização, sistemas e métodos. São Paulo: McGraw Hill.

Associação Brasileira das Empresas de Refeições Coletivas - ABERC. (2017). Mercado real. São Paulo: ABERC. Recuperado em 2018, janeiro 8, de http://www.aberc.com.br/mercadoreal.asp?IDMenu=21

Brasil. Agência Nacional de Vigilância Sanitária - ANVISA. (2004). Estabelece procedimentos de Boas Práticas para serviços de alimentação a fim de garantir as condições higiênico-sanitárias do alimento preparado (Resolução - RDC no 216 , de 15 de setembro de 2004). Diário Oficial [da] República Federativa do Brasil, Brasília.

Brasil. Ministério da Saúde. Secretaria de Vigilância em Saúde - SVS. (2010). Manual integrado de prevenção e controle de doenças transmitidas por alimentos. Brasília: Editora Ministério da Saúde.

Brasil Ministério da Saúde. Secretaria de Vigilância em Saúde - SVS. (2017). Surtos de doenças transmitidas por alimentos no Brasil. Brasília: Ministério da Saúde.Recuperado em 9 de janeiro de 2018, de <http://portalarquivos.saude.gov.br/images/pdf/2017/maio/29/Apresentacao-Surtos-DTA-2017>

Castro, A., Santos, C., Meireles, H., Silva, J., \& Teixeira, P. (2016). Food handlers as potential sources of dissemination of virulent strains of Staphylococcus aureus in the community. Journal of Infection and Public Health, 9(2), $153-160$. PMid:26424093. http://dx.doi.org/10.1016/j.jiph.2015.08.001

Centers for Disease Control and Prevention - CDC. (2013). Commercial dishwashing specification: guideline for mechanical ware washing in foodservice establishments. Atlanta: US Department of Health and Human Services. Recuperado em 8 de janeiro de 2018, de http://www.bccdc.ca/NR/rdonlyres/558797A0-F492-43D7-ACE3-

260D5E726380/0/GuidelinesMechanicalWarewashinginFoodServiceEstablishmentswebformatJan2013.pdf

Centers for Disease Control and Prevention - CDC. (2016). Surveillance for foodborne disease outbreaks, United States, 2016. annual report. Atlanta: US Department of Health and Human Services.

Cerveny, J., Meyer, J. D., \& Hall, P. A. (2009).Microbiological spoilage of meat and poultry products. In W. H. Sperber \& M. P. Doyle (Eds.), Compendium of the microbiological spoilage of foods and beverages (pp. 69-86). New York: Springer. http://dx.doi.org/10.1007/978-1-4419-0826-1_3.

Chaibenjawong, P., \& Foster, S. (2011). Desiccation tolerance in Staphylococcus aureus. Archives of Microbiology, 193(2), 125135. PMid:21088825. http://dx.doi.org/10.1007/s00203-010-0653-x

Chatt, C., Nicholds-Trainor, D., Scrivener, A., Suleman, S., Harvey, M., Dallman, T., Hawker, J., \& Sibal, B. (2017). Outbreak of Salmonella Enteritidis PT14b gastroenteritis at a restaurant in England: the use of molecular typing to achieve a successful prosecution. Public Health, 155, 51-58. PMid:28732304. http://dx.doi.org/10.1016/j.puhe.2017.06.012

Coelho, A. Í. M., Milagres, R. C. R. M., Martins, J. F. L., Azeredo, R. M. C., \& Santana, Â. M. C. (2010). Contaminação microbiológica de ambientes e de superfícies em restaurantes comerciais. Ciencia \& Saude Coletiva, 15(Supl. 1), 1597-1606. PMid:20640321. http://dx.doi.org/10.1590/S1413-81232010000700071

Cohen, J., Powderly, W. G., \& Opal, S. M. (2017). Infectious diseases (4th ed.). USA: Elsevier.

Cunningham, A. E., Rajagopal, R., Lauer, J., \& Allwood, P. (2011). Assessment of hygienic quality of surfaces in retail food service establishments based on microbial counts and real-time detection of ATP. Journal of Food Protection, 74(4), 686-690. PMid:21477489. http://dx.doi.org/10.4315/0362-028X.JFP-10-395

Daskalov, H. (2006). The importance of Aeromonas hydrophila in food safety. Food Control, 17(6), 474-483. http://dx.doi.org/10.1016/j.foodcont.2005.02.009

Ebone, M. V., Cavalli, S. B., \& Lopes, S. J. (2011). Safety and sanitary quality of food services. Revista de Nutrição, 24(5), 725734. http://dx.doi.org/10.1590/S1415-52732011000500006 
Evancho, G. M., Sveum, W. H., Moberg, L. J., \& Frank, J. F. (2001). Microbiological monitoring of the food processing environment. In F. P. Downes \& K. Ito. Compendium of methods for the microbiological examination of foods. Washington: Apha Press.

Gkana, E., Lianou, A., \& Nychas, G. J. (2016). Transfer of Salmonella Enterica Serovar Typhimurium from beef to tomato through kitchen equipment and the efficacy of intermediate decontamination procedures. Journal of Food Protection, 79(7), 1252-1258. PMid:27357047. http://dx.doi.org/10.4315/0362-028X.JFP-15-531

Hennekinne, J.-A., Buyser, M.-L., \& Dragacci, S. (2012). Staphylococcus aureus and its food poisoning toxins: characterization and outbreak investigation. FEMS Microbiology Reviews, 36(4), 815-836. PMid:22091892. http://dx.doi.org/10.1111/j.15746976.2011.00311.x

Heuer, H., \& Smalla, K. (1997). Application of denaturing gradient gel electrophoresis (DGGE) and temperature gradient gel electrophoresis (TGGE) for studying soil microbial communities. In J. D. van Elsas, J. T. Trevors \& E. M. H. Wellington (Eds.), Modern soil microbiology. New York: Marcel Dekker.

Jerônimo, H. M., Queiroga, R. C. R. E., Costa, A. C. V., Barbosa, I. M., Conceição, M. L., \& Souza, E. L. (2011). Occurrence of Staphylococcus spp. and S. aureus on surfaces used for preparing food in a foodservice. Nutrire, 36, 37-48.

Kasnowski, M. C., Mantilla, S. P. S., Oliveira, L. A. T., \& Franco, R. M. (2010). Formação de biofilme na indústria de alimentos e métodos de validação de superfícies. Revista Científica Eletrônica de Medicina Veterinária, 8(15), 1-23.

Kochanski, S., Pierozan, M. K., Mossi, A. J., Treichel, H., Cansian, R. L., Ghisleni, C. P., \& Toniazzo, G. (2009). Avaliação das condições microbiológicas de uma unidade de alimentação e nutrição. Brazilian Journal of Food and Nutrition, 20(4), 663-666.

Kornacki, J. L., \& Johnson, J. (2001). Enterobacteriaceae, coliformns and Escherichia coli as quality and safety indicators. In F. P. Dowes, \& K. Ito (Eds.), Compendium of methods for the microbiological examination of foods (4th ed., pp. 69-82). Washington: American Public Health Association.

Kusumaningrum, H. D., van PUTTEN, M. M., Rombouts, F. M., \& Beumer, R. R. (2002). Effects of antibacterial dishwashing liquid on foodborne pathogens and competitive microorganisms in kitchen sponges. Journal of Food Protection, 65(1), 61-65. PMid:11811157. http://dx.doi.org/10.4315/0362-028X-65.1.61

Leal, D. (2010). Crescimento da alimentação fora do domicílio. Segurança Alimentar e Nutricional, 17(1), $123-132$. http://dx.doi.org/10.20396/san.v17i1.8634806

Leclerc, H., Mossel, D. A., Edberg, S. C., \& Struijk, C. B. (2001). Advances in the bacteriology of the coliform group: their suitability as markers of microbial water safety. Annual Review of Microbiology, 55(1), 201-234. PMid:11544354. http://dx.doi.org/10.1146/annurev.micro.55.1.201

Losasso, C., Cibin, V., Cappa, V., Roccato, A., Vanzo, A., Andrighetto, I., \& Ricci, A. (2012). Food safety and nutrition: Improving consumer behaviour. Food Control, 26(2), 252-256. http://dx.doi.org/10.1016/j.foodcont.2012.01.038

Mattick, K., Durham, K., Hendrix, M., Slader, J., Griffith, C., Sen, M., \& Humphrey, T. (2003). The microbiological quality of washing-up waterand the environment in domestic and commercial kitchens. Journal of Applied Microbiology, 94(5), 842-848. PMid:12694449. http://dx.doi.org/10.1046/j.1365-2672.2003.01904.x

Medeiros, M. G. G. A., Carvalho, L. R., \& Franco, R. M. (2017). Percepção sobre a higiene dos manipuladores de alimentos e perfil microbiológico em restaurante universitário. Ciencia \& Saude Coletiva, 22(2), 383-392. http://dx.doi.org/10.1590/141381232017222.17282015

Møretrø, T., \& Langsrud, S. (2017). Residential bacteria on surfaces in the food industry and their implications for food safety and quality. Comprehensive Reviews in Food Science and Food Safety, 16(5), 1022-1041. http://dx.doi.org/10.1111/15414337.12283

Muyzer, G., Waal, E. C., \& Uitterlinden, A. G. (1993). Profiling of complex microbial populations by denaturing gradient gel electrophoresis analysis of polymerase chain reaction-amplified genes coding for $16 \mathrm{~S}$ rRNA. Applied and Environmental Microbiology, 59(3), 695-700. PMid:7683183.

Neely, A. N., \& Maley, M. P. (2000). Survival of Enterococci and Staphylococci on hospital fabrics and plastic. Journal of Clinical Microbiology, 38(2), 724-726. PMid:10655374.

Oliveira, A. B. A., Paula, C. M. D., Capalonga, R., Cardoso, M. R. I., \& Tondo, E. C. (2010). Doenças transmitidas por alimentos, principais agentes etiológicos e aspectos gerais: uma revisão. Revista do Hospital de Clínicas e da Faculdade de Medicina Publica, 30(3), 279-285.

Peleg, A., Seifert, H., \& Paterson, D. (2008). Acinetobacter baumannii: emergence of a successful pathogen. Clinical Microbiology Reviews, 21(3), 538-582. PMid:18625687. http://dx.doi.org/10.1128/CMR.00058-07

Rezende, C., Seemann, C. F., Sivla, E. S., Jacobucci, H. B., \& Mattar, M. (2012). Superfície inanimada - possível fonte de contaminação microbiológica no alimento. Revista Brasileira de Farmácia, 93(4), 444-449.

Rode, T. M., Langsrud, S., Holck, A., \& Møretrø, T. (2007). Different patterns of biofilm formation in Staphylococcus aureus under food related stress conditions. International Journal of Food Microbiology, 116(3), 327-383. PMid:17408792. http://dx.doi.org/10.1016/j.ijfoodmicro.2007.02.017

Rodrigues, F. S., \& Sabes, J. J. S. (2006). A percepção do consumidor de alimentos "fora de casa": um estudo multicaso na cidade de Campo Grande/MS. Caderno de Administração, 14(2), 37-45.

São José, J. F. B. (2012). Microbiological contamination in food service : importance and control. Nutrire, 37(1), 78-92. 
Condições higiênico-sanitárias e perfil da comunidade microbiana de utensílios e mesas higienizadas de um serviço de alimentação localizado no Rio de Janeiro

Oliveira, A. G. M. et al.

Scarcella, A. C. A., Scarcella, A. S. A., \& Beretta, A. L. R. Z. (2016). Infecção relacionada à assistência à saúde associada à Acinetobacter baumannii: revisão de literatura. Revista Brasileira de Análises Clínicas. http://dx.doi.org/10.21877/24483877.201600361

Silva Junior, E. A. (2007). Manual de controle higiênico-sanitário em serviços de alimentação. São Paulo: Ed. Livraria Varela.

Silva, M. L. Q., Aquino, P. E. A., Leandro, L. M. G., Alves, F. M., Barros, F. C. N., \& Vandesmet, V. C. S. (2014). Análise microbiológica de pratos e talheres em self-services e restaurantes populares da cidade de Juazeiro do Norte - Ceará. Revista Saúde e Pesquisa, 7(3), 445-454.

Silva, M. P., Cavalli, D. R., \& Oliveira, T. C. R. M. (2006). Avaliação do padrão coliformes a $45^{\circ} \mathrm{C}$ e comparação da eficiência das técnicas dos tubos múltiplos e Petrifilm EC na detecção de coliformes totais e Escherichia coli em alimentos. Food Science and Technology (Campinas), 26(2), 352-359. http://dx.doi.org/10.1590/S0101-20612006000200018

Wolde, T., \& Bacha, K. (2016). Microbiological safety of kitchen sponges used in food establishments. International Journal of Food Sciences, 2016, 1-7. PMid:27840819. http://dx.doi.org/10.1155/2016/1659784

Wong, D., Nielsen, T. B., Bonomo, R. A., Pantapalangkoor, P., Luna, B., \& Spellberg, B. (2017). Clinical and pathophysiological overview of Acinetobacter Infections: a century of challenges. Clinical Microbiology Reviews, 30(1), 409-447. PMid:27974412.

World Health Organization - WHO. (2018). Foodborne outbreaks: guidelines for investigation and control. Recuperado em 9 de janeiro de 2018, de http://www.who.int/foodsafety/publications/foodborne_disease/outbreak_guidelines.pdf

Zhang, Q., Shi, G.-Q., Tiang, G.-P., Zou, Z.-T., Yao, G.-H., \& Zeng, G. (2012). A foodborne outbreak of Aeromonas hydrophila in a college, Xingyi City, Guizhou, China, 2012. Western Pacific Surveillance and Response Journal : WPSAR, 3(4), 39-43. PMid:23908938. http://dx.doi.org/10.5365/wpsar.2012.3.4.018

Financiamento: Fundação de Amparo à pesquisa do Rio de Janeiro (FAPERJ) pelo suporte financeiro, através do Edital $n^{\circ}$ 05/2010 - Processo E-26 / 111.142/2010 e Edital n 14/2012 EXTPESQ - Processo E-26/111.540/2012; Universidade Federal do Rio de Janeiro pela concessão de bolsas A07.2013.1 - PB039 e A07.2016.1 - PB054. 